\title{
Retinopathy of prematurity: Postnatal weight gain and risk factors profile; a hospital-based study from a tertiary care center
}

\author{
Pooja Subramanya $^{1}$, G C M Pradeep ${ }^{2}$, M Sharanabasavesh ${ }^{3}$, M V Krithika ${ }^{4}$ \\ From ${ }^{1}$ Junior Resident, ${ }^{2}$ Professor and Head, ${ }^{3}$ Associate Professor, ${ }^{4}$ Assistant Professor, Neonatal Unit, Department of Pediatrics, Ramaiah Medical \\ College and Hospitals, Bangalore, Karnataka, India
}

\begin{abstract}
Background: Premature infants often develop blindness in one or both eyes due to disparity in retinal growth. This condition is termed as retinopathy of prematurity (ROP). Aim: The aim of the study is to study the postnatal weight gain pattern of preterm infants (Age $<32$ weeks) and risk factors of ROP in a tertiary care center and to validate the lower birth weight and gestational age (GA) for ROP. Methods: Hospital-based study on 110 preterm neonates admitted in the neonatal intensive care unit (NICU) who fulfilled the criteria for ROP screening. On screening, 55 neonates were identified to have ROP and 55 neonates identified to have no ROP. The profiles of ROP and risk factors were documented according to the International Classification for ROP recommendations. The data were analyzed for GA, birth weight, and risk factors predisposing to ROP. Results: A total of 110 preterm neonates were screened, out of which, 55 had ROP. The mean GA $(P=0.002)$, Apnea $(P=0.001)$, ventilation $(P=0.001)$, and surfactant $(P=0.001)$ were observed a significant difference. Further, a significant difference in weight gain pattern in the two groups $(P<0.05)$ was also observed. The group without ROP had a better weight gain pattern than the group with ROP. Conclusion: Our study revealed prematurity, low birth weight, and birth weight increasing patterns were found to be strong predictors of ROP. GA, apnea, ventilation, and surfactant were found to be statistically significant factors associated with ROP.
\end{abstract}

Key words: Retinopathy of Prematurity, Prematurity, Birth weight, Gestational age

$\mathrm{R}$ etinopathy of prematurity (ROP) is a complex disease which cause blindness in one or both eyes of premature infants due to the disorganized growth of retinal blood vessels [1]. Several investigators have identified several risk factors for ROP, such as low birth weight, hypoxia, duration of oxygen supplementation, respiratory distress syndrome, twin pregnancy, anemia, blood transfusions, sepsis, intraventricular hemorrhage, hypotension, hypothermia, maternal factors, and prenatal and perinatal factors $[2,3]$. Among these, birth weight and gestational age (GA) are the two major risk factors to screen the disease [4]. After preterm birth, the loss of placental supply of nutrients and reduction of infant growth factors (IGF) are the major reasons to develop ROP [5]. ROP is a leading cause of preventable childhood blindness with over 3,00,000 neonates affected with the incidence of $24 \%-47 \%$ worldwide [6]. Among these, one-fourth of the blind children live in India. The WHO suggests that India and other middle-income countries are suffering from the 'third epidemic' of this disease [7]. In India, the incidence of ROP varies in different geographical regions: $22.3 \%$ in Pune, Maharashtra [8], 16\% in

\section{Access this article online}

Received - 05 July 2021

Initial Review - 03 August 2021

Accepted - 06 September 2021

DOI: $10.32677 / \mathrm{IJCH} .2021 . v 08.109 .3051$
Shimla, Himachal Pradesh [9], 24.1\% in Vadodara, Gujarat [10], $44 \%$ in Kalyani, West Bengal [11], 21.3\% in Srinagar [12], 73.6\% in New Delhi [13], 33.2\% in Eastern India [14].

According to the American Academy of Pediatrics (AAP), neonates with birth weight $<1500 \mathrm{~g}$ or $\mathrm{GA} \leq 30$ weeks should undergo retinal screening [15]. However, in India, the GA of infants are not always known or accurate. Even babies with body weight $>1600 \mathrm{~g}$ and GA $>32$ weeks also fall prey to develop ROP and sometimes severe ROP [16]. In India, due to lack of proper screening guidelines, and other unknown etiologies for ROP, often contradictory reports are obtained. However, there is a paucity of population-based-ROP in these larger neonates. Further, there are no studies in our country aiming to validate the post-natal weight gain pattern to predict the development of severe ROP. The present study aimed to find the postnatal weight gain, record the profile of ROP, and to identify the risk factors associated with the development of ROP in our population.

\section{MATERIALS AND METHODS}

A total of 110 preterm infants were included. All infants underwent screening for ROP, had their weight measured every week,

Correspondence to: Dr. Krithika MV, Department of Pediatrics, Ramaiah Medical College and Hospitals, New BEL Road, MSRIT Post, Bangalore - 560054 , Karnataka, India. E-mail: krithika.mv@gmail.com

(C) 2021 Creative Commons Attribution-NonCommercial 4.0 International License (CC BY-NC-ND 4.0). 
and recorded for the survival to the final ophthalmologic ROP assessment. Based on the ROP screening, the included infants were divided into two groups: Infants with ROP (55 preterm infants) and infants without ROP (55 preterm infants). Neonates with GA at delivery $<23$ or $>31+6$ weeks, incomplete weight entry, no final ROP outcome, and preterm infants who were discharged or died before 4 weeks of life were excluded from the study. GA $<32$ weeks and/or a birth weight $(\mathrm{BW}) \leq 1500 \mathrm{~g}$ who stayed in NICU for minimum period of 4 weeks and had been screened for ROP were included for this study. Ethical clearance was obtained from the institutional ethics committee and informed consent was collected from all the guardians and/or the parents of the participants prior to the study. Infant's demographics, GA, gender and birth weight, other probable risk factors for the development of ROP such as oxygen exposure (ventilation), blood transfusions, surfactant, and apnea were documented. Each weekly weight had been entered into the WINROP algorithm measured at exactly $1^{\text {st }}, 2^{\text {nd }}, 3^{\text {rd }}$, and $4^{\text {th }}$ week of postnatal age.

Infants who were eligible for ROP examination, according to the American Academy Pediatrics and National Neonatology Forum guidelines [17], were examined by ophthalmologists and categorized following the International Classification of ROP. All the babies were followed up till the time of the first ROP screening or WINROP alarm or till the retina was fully vascularized, whichever was later.

All the quantitative variables such as BW, GA, and mean weight gain are expressed in mean \pm standard deviation (SD). Mean weight gain in both cohorts was estimated and tested for statistical significance through Friedman test. Chi-square test was used to predict the association between the other risk factors and the development of ROP. Multiple logistic regressions were used to find the independent risk factors for the development of ROP. Mann-Whitney test was used to test the statistical significance of the difference in the median duration of total parenteral nutrition (TPN) and median age of reaching full feeds in the two groups. All the statistical analysis was done using the SPSS v.16 software.

\section{RESULTS}

ROP screening was carried out for a total of 110 infants of which, 55 had ROP and the remaining 55 did not have ROP. The clinical characteristics of study participants between the infants with/ without ROP group were documented in Table 1. The mean GA, apnea, ventilation, and surfactant were observed to have a significant difference between the with/without ROP groups studied. However, the other studied risk factors for ROP such as mean BW, blood transfusion, and continuous positive airway pressure (CPAP) were not found to have a significant difference between the studied groups (Table 1).

The BW and weight gain at different weeks were documented in Table 2. There was a significant difference was observed between the groups for BW and weight loss of infants in the first week after birth. Furthermore, the mean weight gain in those without ROP was found to be significantly higher as compared to those with ROP.
The TPN and age to full feeds between with ROP and without ROP were documented in Table 3.

The longitudinal postnatal weight gain pattern in the two groups is presented in Fig. 1. There was a significant difference in weight gain pattern between the two groups ( $<<0.05$ ). The group without ROP had a better weight gain pattern than the group with ROP.

\section{DISCUSSION}

In India, several studies on ROP were conducted. However, the screening method and incidence rate of ROP varies widely throughout the country. A study conducted by Nitin Kumar et al., [9] based in Shimla, Himachal Pradesh screened 50 babies; the mean BW of the ROP babies was $1043 \mathrm{~g}$ while that of nonROP babies was 1334 gms. Lower BW was significantly associated with increased incidence $(\mathrm{p}=0.007)$ and severity $(\mathrm{p}=0.017)$ of ROP. The mean GA of the ROP babies was 30.63 weeks while that of non- ROP babies was 32.1 weeks. Similarly, another study from

Table 1: Clinical characteristics of study participants between the infants with/without ROP group

\begin{tabular}{lccc}
\hline Risk factors & $\begin{array}{c}\text { Infants } \\
\text { with ROP } \\
\mathbf{n = 5 5}\end{array}$ & $\begin{array}{c}\text { Infants } \\
\text { without ROP } \\
\mathbf{n = 5 5}\end{array}$ & p value* \\
\hline Mean gestational age (weeks) & 29.35 & 31.27 & 0.002 \\
$\begin{array}{l}\text { Mean birth weight (gms) } \\
\text { Apnea; number (percentage) }\end{array}$ & $24(44 \%)$ & $12(22 \%)$ & $<0.01$ \\
$\begin{array}{l}\text { Blood transfusion; number } \\
\text { (percentage) }\end{array}$ & $34(76 \%)$ & $11(23 \%)$ & 0.12 \\
$\begin{array}{l}\text { Ventilation; number } \\
\text { (percentage) }\end{array}$ & $39(71 \%)$ & $15(29 \%)$ & 0.001 \\
$\begin{array}{l}\text { CPAP; number (percentage) } \\
\begin{array}{l}\text { Surfactant; number } \\
\text { (percentage) }\end{array}\end{array}$ & $20(76 \%)$ & $15(23 \%)$ & 0.119 \\
\hline $\begin{array}{l}\text { CPAP: Continuous positive airway pressure, *p value obtained from Chi square test. } \\
\text { ROP: Retinopathy of prematurity }\end{array}$ & $34(62 \%)$ & $9(16 \%)$ & $<0.01$ \\
\end{tabular}

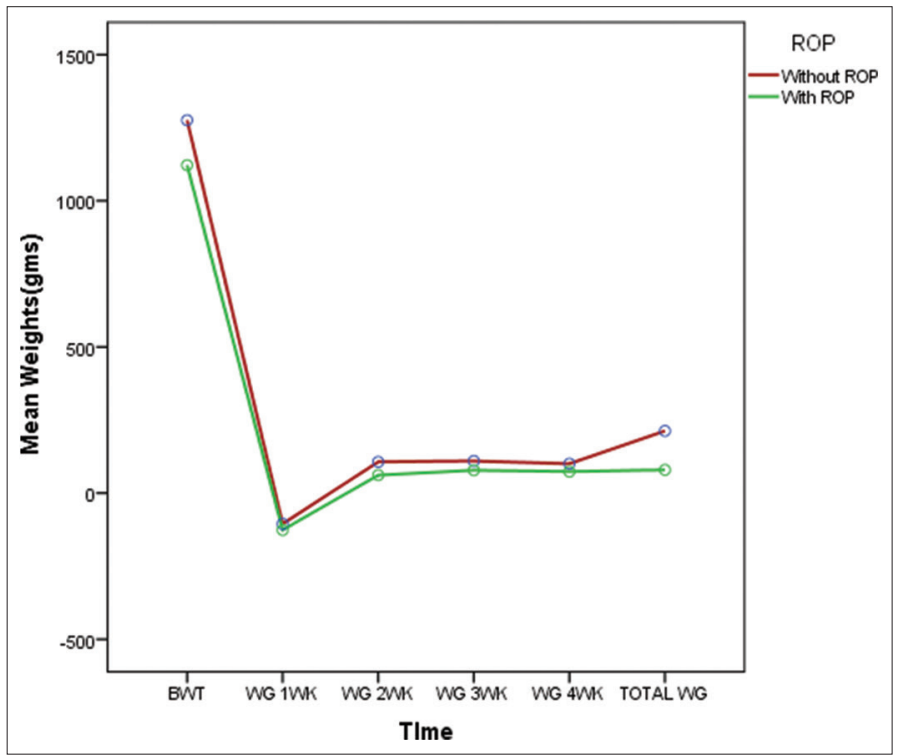

Figure 1: Postnatal weight gain pattern in the ROP and non-ROP groups 
Table 2: Weight gain association between the infants with/without ROP at different weeks

\begin{tabular}{|c|c|c|c|c|c|c|}
\hline \multirow[t]{2}{*}{ Characteristics } & \multirow[t]{2}{*}{ Birth weight (g) } & \multicolumn{4}{|c|}{ Weight gain (g) at the end of } & \multirow[t]{2}{*}{ Mean weight gain (g) } \\
\hline & & Week 1 & Week 2 & Week 3 & Week 4 & \\
\hline \multicolumn{7}{|l|}{ With ROP } \\
\hline Mean & 1122.18 & -126.22 & 61.49 & 78.18 & 73.45 & 79.27 \\
\hline SD & 187.03 & 79.57 & 69.18 & 65.80 & 55.11 & 137.63 \\
\hline \multicolumn{7}{|l|}{ Without ROP } \\
\hline Mean & 1275.91 & -105.45 & 106.91 & 109.82 & 100.55 & 212.55 \\
\hline SD & 192.30 & 68.30 & 49.81 & 57.26 & 48.43 & 96.67 \\
\hline $\mathrm{p}$ value* & $<0.000$ & $<0.038$ & $<0.000$ & $<0.001$ & $<0.005$ & $<0.000$ \\
\hline
\end{tabular}

ROP: Retinopathy of prematurity, SD: Standard deviation, p value*: Probability value obtained from Friedman test

Table 3: The duration of TPN and age of reaching full feeds in the two groups with and without ROP

\begin{tabular}{lccc}
\hline Characteristics & $\begin{array}{c}\text { With ROP } \\
\text { median (range) }\end{array}$ & $\begin{array}{c}\text { Without ROP } \\
\text { median (range) }\end{array}$ & p value* \\
\hline TPN (days) & $0(0-27)$ & $10(0-25)$ & $<0.01$ \\
$\begin{array}{l}\text { Age at full } \\
\text { feeds (days) }\end{array}$ & $28(3-54)$ & $17(7-42)$ & 0.001 \\
\hline
\end{tabular}

ROP: Retinopathy of prematurity, $p$ value*: Probability value obtained from Mann-Whitney test; TPN: Total parenteral nutrition

Gujarat found a significant difference between mean BW of ROP positive cases (1622.38 \pm 612.89$)$. Further, the GA of ROP positive versus negative cases was also observed to have a significant difference $(\mathrm{p}<0.001)(10)$. A study from Srinagar was also found the mean GA of patients who developed ROP was $29.0 \pm 2.52$ weeks and who did not develop ROP was $32.7 \pm 3.08$. The mean weight of ROP positive group was $1.36 \pm 0.255 \mathrm{~kg}$ and ROP negative group was $1.67 \pm 0.227 \mathrm{~kg}$ [12]. Furthermore, studies from the Indian sub-continent such as in Pune, Maharashtra [8], Kalyani, West Bengal [11], Srinagar [12], New Delhi [13], and in Eastern India [14], also reported similar kind of results. In accordance with these previous reports, our study also found a significant difference of GA between the ROP and non-ROP group. However, the mean BW of infants were not significantly different.

In our study, low BW was found to be significantly correlated with the incidence of ROP, which is in agreement with the other studies conducted internationally such as in neonates from Oman [18], Egypt [19], Iran [20], Southeastern Turkey [21], Singapore [22], USA [23], Australia, and New Zealand [24]. Several risk factors have been reported to predispose to the development of ROP [25,26]. In our study, apnea, ventilation, and surfactant were found to be the significant risk factors in accord with other studies from India. Chaudhari et al., found that apnea and septicemia are the risk factors for ROP [8]. Vinekar, et al. [16] also found that septicemia was a significant risk factor. Aggarwal et al., [27] found apnea, clinical sepsis, and male sex to be significant risk factors. In our study, we found that the surfactant was significant risk factor for ROP in accord with the study by Seiberth, et al. [28]. In contrast, the study from pune, India by Chaudhari et al., did not find any significant association for surfactant [8]. Chauhan et al. [12] found that blood transfusion is a significant risk factor, whereas our study and the study by Nitin kumar et al. [9] did not find any such association.
Several studies revealed that poor postnatal weight gain is a predictor of the severe development of ROP [29-31]. However, studies have measured the weight analysis using the relative weight gain $(\mathrm{g} / \mathrm{kg} / \mathrm{d})$ through 6 weeks, correlating the low weight gain and risk for the ROP development by WINROP and PINTROP methods [31-33]. In previous studies concerning with low BW standard deviation score (BWSDS) as a risk factor for ROP, infants were grouped differently and results have been inconclusive [24,34-36]. However, Qui et al. [37] reported that the impact of small GA as a risk factor for severe ROP varies for infants born $\leq 26,27-28,29-30$, or 31-32 weeks GA. On the other hand, these studies did not correlate the development and severity of ROP. Consequently, differences among study results concerning low BWSDS as a risk factor for ROP may depend on the infants' GA at birth. Similarly, in our study also the postnatal weight gain was correlated with ROP. However, we have collected nutritional data to point out a particular nutrients function with the development of ROP. The highest number of preterm deliveries with burden of ROP was found in India compared to the other countries in the world [38]. Timely screening for ROP and proper treatments following the international guidelines could help in reducing the burden of ROP in India. However, the current study was conducted with a small sample size and thus may not represent all premature infants. Moreover, there was lack of nutritional data to correlate with ROP and severity. To find the proper screening, treatment, and method of screening and to know the exact incidence and risk factors involved for ROP, it is recommended to include larger sample size along with multicentric collaboration for the Indian geographic region.

\section{CONCLUSION}

The current study found a significant association of ROP with the GA, apnea, ventilation, surfactant, weight gain at different week follow-up, and TPN and age at full feed. Further, it can be concluded that there exists a correlation between the longitudinal postnatal weight gain pattern of preterm infants $<32$ weeks and the incidence of severe ROP. It can also be concluded that slowing postnatal weight gains is an independent predictor of the development of ROP and postnatal weight gain analysis can help to identify infants at high risk for developing treatable ROP, as well as identify those not at risk. However, studies with a larger 
number of samples along with multicentric study will further confirm our results.

\section{REFERENCES}

1. Sapieha P, Joyal JS, Rivera JC, Kermorvant-Duchemin E, Sennlaub F, Hardy P, et al. Retinopathy of prematurity: Understanding ischemic retinal vasculopathies at an extreme of life. J Clin Invest 2010;120:3022-32.

2. Edy Siswanto J, Sauer PJ. Retinopathy of prematurity in Indonesia: Incidence and risk factors. J Neonatal Perinatal Med 2017;10:85-90.

3. Alajbegovic-Halimic J, Zvizdic D, Alimanovic-Halilovic E, Dodik I, Duvnjak S. Risk factors for retinopathy of prematurity in premature born children. Med Arch 2015;69:409-13.

4. Kim SJ, Port AD, Swan R, Campbell JP, Chan RVP, Chiang MF. Retinopathy of prematurity: A review of risk factors and their clinical significance. Surv Ophthalmol 2018;63:618-37.

5. Lofqvist C, Andersson E, Sigurdsson J, Engstrom E, Hard AL, Niklasson A, et al. Longitudinal postnatal weight and insulin-like growth factor I measurements in the prediction of retinopathy of prematurity. Arch Ophthalmol 2006;124:1711-8.

6. Khatami SF, Yousefi A, Bayat GF, Mamuri G. Retinopathy of prematurity among 1000-2000 gram birth weight newborn infants. Iran J Pediatr 2008; 18:137-42.

7. Gilbert C, Foster A. Childhood blindness in the context of VISION 2020-the right to sight. Bull World Health Organ. 2001;79(3):227-32.

8. Chaudhari S, Patwardhan V, Vaidya U, Kadam S, Kamat A. Retinopathy of prematurity in a tertiary care center-incidence, risk factors and outcome. Indian Pediatr 2009;46:219-24.

9. Kumar N, Kaushik SL, Grover N, Sharma RL. Retinopathy of prematurity: Incidence and risk factors: A hospital based study from Shimla, Himachal Pradesh, India. Int J Res Med Sci 2016;5:56-61.

10. Patel SS, Shendurnikar N. Retinopathy of prematurity in India: Incidence, risk factors, outcome and the applicability of current screening criteria. Int J Contemp Pediatr 2019;6:2235-41.

11. Chattopadhyay MP, Pradhan A, Singh R, Datta S. Incidence and risk factors for retinopathy of prematurity in neonates. Indian Pediatr 2015;52:157-8.

12. Chauhan M, Ahmad S, Shafi T, Malik S. Retinopathy of prematurity, a hospital based study. Int J Contemp Med Res 2019;6:B5-9.

13. Sachan A, Chandra P, Agarwal R, Vohra R, Chawla R, Sankar MJ, et al. Profile of retinopathy of prematurity in outborn and inborn babies at a tertiary eye care hospital. Indian Pediatr 2020;57:1020-2.

14. Padhi TR, Jain L, Behera UC, Pradhan L. Retinopathy of prematurity profile and trend over the years: Experience from a two tier city in Eastern India. Indian Pediatr 2016;53 Suppl 2:S76-9.

15. Fierson WM, American Academy of Pediatrics Section on Ophthalmology, American Academy of Ophthalmology, American Association for Pediatric Ophthalmology and Strabismus, American Association of Certified Orthoptists. Screening examination of premature infants for retinopathy of prematurity. Pediatrics 2018;142:e20183061.

16. Vinekar A, Dogra MR, Sangtam T, Narang A, Gupta A. Retinopathy of prematurity in Asian Indian babies weighing greater than 1250 grams at birth: Ten year data from a tertiary care center in a developing country. Indian J Ophthalmol 2007;55:331-6.

17. Fierson WM, American Academy of Pediatrics Section on Ophthalmology, American Academy of Ophthalmology, American Association for Pediatric Ophthalmology and Strabismus; American Association of Certified Orthoptists, Screening examination of premature infants for retinopathy of prematurity. Pediatrics 2013;131:189-95.

18. Bassiouny MR. Risk factors associated with retinopathy of prematurity: A study from Oman. J Trop Pediatr 1996;42:355-8.

19. Hadi AM, Hamdy IS. Correlation between risk factors during the neonatal period and appearance of retinopathy of prematurity in preterm infants in neonatal intensive care units in Alexandria, Egypt. Clin Ophthalmol 2013;7:831-7.
20. Feghhi M, Altayeb SM, Haghi F, Kasiri A, Farahi F, Dehdashtyan M, et al. Incidence of retinopathy of prematurity and risk factors in the South-Western region of iran. Middle East Afr J Ophthalmol 2012;19:101-6.

21. Sahin A, Sahin M, Turkcu FM, Cingu AK, Yuksel H, Cinar Y, et al. Incidence of retinopathy of prematurity in extremely premature infants. ISRN Pediatr 2014;2014:134347.

22. Shah VA, Yeo CL, Ling YL, Ho LY. Incidence, risk factors of retinopathy of prematurity among very low birth weight infants in Singapore. Ann Acad Med Singap 2005;34:169-78.

23. Chen M, Citil A, McCabe F, Leicht KM, Fiascone J, Dammann CE, et al. Infection, oxygen, and immaturity: Interacting risk factors for retinopathy of prematurity. Neonatology 2011;99:125-32.

24. Darlow BA, Hutchinson JL, Henderson-Smart DJ, Donoghue DA, Simpson JM, Evans NJ, et al. Prenatal risk factors for severe retinopathy of prematurity among very preterm infants of the Australian and New Zealand Neonatal network. Pediatrics 2005;115:990-6.

25. Sangtam T, Vinekar A, Maheshwar B, Dogra MR, Eong KG. Intravitreal bevacizumab (Avastin) for post-laser photocoagulation anterior segment ischemia in aggressive posterior retinopathy of prematurity. Indian $\mathrm{J}$ Ophthalmol 2007;55:317; author reply 317-8.

26. Dutta S, Narang S, Narang A, Dogra M, Gupta A. Risk factors of threshold retinopathy of prematurity. Indian Pediatr 2004;41:665-71.

27. Aggarwal R, Deorari AK, Azad RV, Kumar H, Talwar D, Sethi A, et al. Changing profile of retinopathy of prematurity. J Trop Pediatr 2002;48:239-42.

28. Seiberth V, Linderkamp O. Risk factors in retinopathy of prematurity. A multivariate statistical analysis. Ophthalmologica 2000;214:131-5.

29. Allegaert K, Vanhole C, Casteels I, Naulaers G, Debeer A, Cossey V, et al. Perinatal growth characteristics and associated risk of developing threshold retinopathy of prematurity. J AAPOS 2003;7:34-7.

30. Wallace DK, Kylstra JA, Phillips SJ, Hall JG. Poor postnatal weight gain: A risk factor for severe retinopathy of prematurity. J AAPOS 2000;4:343-7.

31. Hellstrom A, Hard AL, Engstrom E, Niklasson A, Andersson E, Smith L, et al. Early weight gain predicts retinopathy in preterm infants: New, simple, efficient approach to screening. Pediatrics 2009;123:e638-45.

32. Hellstrom A, Perruzzi C, Ju M, Engstrom E, Hard AL, Liu JL, et al. Low IGF-I suppresses VEGF-survival signaling in retinal endothelial cells: Direct correlation with clinical retinopathy of prematurity. Proc Natl Acad Sci USA 2001;98:5804-8.

33. Binenbaum G, Ying GS, Quinn GE, Dreiseitl S, Karp K, Roberts RS, et al. A clinical prediction model to stratify retinopathy of prematurity risk using postnatal weight gain. Pediatrics 2011;127:e607-14.

34. Group E. Incidence of and risk factors for neonatal morbidity after active perinatal care: Extremely preterm infants study in Sweden (EXPRESS). Acta Paediatr 2010;99:978-92.

35. Zaw W, Gagnon R, da Silva O. The risks of adverse neonatal outcome among preterm small for gestational age infants according to neonatal versus fetal growth standards. Pediatrics 2003;111:1273-7.

36. Woo SJ, Park KH, Ahn J, Oh KJ, Lee SY, Jeong EH, et al. A co-twin study of the relative effect of birth weight and gestational age on retinopathy of prematurity. Eye 2011;25:1478-83.

37. Qiu X, Lodha A, Shah PS, Sankaran K, Seshia MM, Yee W, et al. Neonatal outcomes of small for gestational age preterm infants in Canada. Am J Perinatol 2012;29:87-94

38. Lawn JE, Kinney MV, Belizan JM, Mason EM, McDougall L, Larson J, et al. Born too soon: Accelerating actions for prevention and care of 15 Million newborns born too soon. Reprod Health 2013;10 Suppl 1:S6.

Funding: None; Conflicts of Interest: None Stated.

How to cite this article: Subramanya P, Pradeep GCM, Sharanabasavesh M, Krithika MV. Retinopathy of prematurity: Postnatal weight gain and risk factors profile; a hospital-based study from a tertiary care center. Indian J Child Health. 2021; 8(9):324-327. 